\title{
Evaluating the Effectiveness of Using Sport and Traditional Games at the Higher Military Educational Establishments in a Pandemic and Post-pandemic Period
}

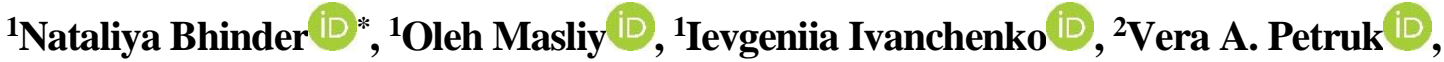 \\ ${ }^{1}$ Nataliia Bachynska \\ ${ }^{1}$ Military Academy (Odesa), Odesa, Ukraine. ${ }^{2}$ Vinnytsia National Technical University, Vinnytsia, \\ Ukraine.
}

Submitted 27 September 2021; Accepted in final form 02 December 2021.

\begin{abstract}
Background. The cadets experienced particular difficulties in a pandemic period because due to isolation and faced a number of unanticipated challenges like stress, anxiety, and low learning outcomes. Objectives: The aim of the study was to evaluate the effectiveness of sport and traditional games to improve cadets' learning performance and motivation to learning activities and future service duties. Methods. The pedagogical experiment was organized at the Military Academy (Odesa, Ukraine) during the 2020-2021 academic year. The research group, on the basis of empirical research, designed the leisure time activities program using five categories of exercises: classical sport team games, individual sports, well-known Ukrainian traditional games; unknown foreign traditional games, and martial arts. Results. During 20 weeks the researchers observed EG and CG groups conducting interviews, analyzing cadets' behavior, monitoring their learning outcomes. The experiment findings revealed that the usage of sport and traditional games was an effective psychological and pedagogical technique to improve the learning process at the higher military educational establishment. On average, the technology effectiveness showed that qualitative changes by three points more. The largest increases were identified for high (3,6 points) and moderate degrees of effectiveness (7,8 points). At the same time, self-organized or poor-organized leisure leads to minor improvements in psychological condition and cognitive abilities among the cadets. Conclusion. Consequently, the usage of sport and traditional games would be an effective instrument applied in a post-pandemic period at the higher military educational establishments. Also, the study presented the recommendations to implement the games during the learning process at the higher military educational establishments.
\end{abstract}

KEYWORDS: Sport and Traditional Games, Future Military Officers, Stress Management, Learning Outcomes, Higher Military Educational Establishment, COVID-19.

\section{INTRODUCTION}

The COVID-19 pandemic has become an additional issue that is very disruptive for the society creating unprecedented challenges in all spheres of national activity (1-3), including the sector of defense and security. The constant expansion of this negative phenomena causes the necessity to increase the readiness of future officers to overcome successfully extreme and uncertain situations. Considering that modernization of the education system, healthcare, and culture is proclaimed one of the priorities of national interests, the special

*. Corresponding Author:

Nataliya Bhinder

E-mail: berestetskanat@ukr.net 
attention is paid towards the improvement of professional training of future military officers.

The cadets face a number of difficulties like imperative communication, increased physical and psychological load, greater demands on daily performance $(2,4,5)$. All these challenges can lead to significant stress and affect the cadets' attitudes to future service. S. Sharma (2015) (4) thinks the professional training of future officers differs in a considerable amount of work, seldom breaks, long learning hours, numerous tasks that can cause negative psychological states like fatigue, anxiety, and nervousness. Cadets' life, where high-level control and subordination dominate, sometimes makes the young people feel disappointed. Such feelings decrease motivation to learning activities and generate negative emotional energy. And the development of science and technology are gradually removing boundaries between a workplace and home. This also applies to the cadets as extensive use of information and communications technologies, interactive techniques for organization of independent work increases the time required for learning activities, especially given for self-paced learning modules.

The pandemic had a significant impact on people's well-being as they were isolated from their relatives and friends because of imposing lockdown measures (6). The same applies to the cadets. Some findings showed that there is increasing recognition of the need to understand the psychological impact of COVID-19 experiences and stress (7). The cadets faced fear and anxiety; they are worried about their own health and health of family members.

According to some findings (7-11), such conditions can be a serious obstacle to future military professional activities causing permanent anticipation of danger and prolonged feeling of loneliness. In addition, low intensity conflict existing in the east of Ukraine requires special psychological training including formation of specific psychological characteristics and permanent operational readiness. Other works (12) show that military officers within the units deployed along the contact line face serious psychological issues. Other stressful situations relate to the change of combat situation, troop movements, changes in leadership or team replacement, change in residence and content of service obligations (9).
A number of scholars studied innovative technologies used in the process of professional training of future military officers $(4,13,14)$. As a result, we have come to the conclusion that different physical activities are very helpful to stabilize psychological condition. These exercises have psychological and physical influence upon a person through doing physical movements, relaxing exercises and rhythmic techniques. The usage of such technologies contributes to establishing of positive social interaction within cadets' groups, increases their emotional stability, develops positive views, improves physical endurance and increases the level of adaptation to existing situation, builds social support, tranquility, openness, and morality. Also, the implementation of traditional movement games restores traditional values among future military officers.

\section{MATERIALS AND METHODS}

To evaluate the effectiveness of sport and traditional games for learning purposes we used a combination of qualitative (traditional pedagogical method, scientific sources analysis, pedagogical observation, generalization of pedagogical experience) and quantitative methods (mathematical and statistical methods, pedagogical experiment, pedagogical testing, modeling, empirical methods including interviews and processing of obtained data) to define the pedagogical problem, to develop the research criteria and indicators, and to calculate the dynamics of values and to verify the results.

Based on the analysis of scientific literature (5, 15-18), we generated the hypothesis that sport and traditional games can be effective during the learning process to form stress management skills among the cadets and increase their educational outcomes. To evaluate the effectiveness of additional physical activities we formed two groups of participants. Experimental group (EG) involved 89 first-year cadets; they were involved in leisure activities with the use of sport and traditional games under supervision of faculty members or peers. 67 first-year cadets from control group (CG) were trained in accordance with approved curriculum and during their free time they were doing usual things. The activities for CG were not planned, supervised or facilitated.

The Choice of Sport and Traditional Games. Sport and traditional games are aimed 
towards improvement of psychological state among different categories of people. Some findings show that such activity demonstrate considerable effectiveness among first-year cadets or during basic training $(19,20)$. It is because the special attention is paid towards cadets' leisure activities in the process of professional training. Sport and traditional games can contribute to restoration of physical, emotional, and intellectual potential, formation of outlook and culture of future military officers.

Sport and other types of games are important components of leisure when cadets study at the higher military educational establishments (2124). Sometimes in the process of professional training of future experts so-called semi-leisure activities are introduced (25) because wellprepared organization of spare time influences greatly their full development and it contributes to formation of future officer's personality. And therefore, the faculty members advise the cadets what activities to choose or explain what exercises are predictably good for restoring of potentials and encourage to learning and professional activities. The infrastructure of educational establishment allows young people to do different physical exercises regularly.

Physical activities are generally divided into traditional games (26) and classical sport exercises that are popular among young people (5, 16). Besides, we took into consideration the ideas of some scholars $(15-17,24)$, dividing traditional sports into traditional martial arts and traditional games. We decided to divide the games into five categories: classical sport team games that are the most popular among young people, individual sports not included in training programs, wellknown Ukrainian traditional games; foreign traditional games; martial arts. At first, the cadets played different games freely; and afterwards they were asked to describe their attitudes towards the exercises. Table 1 shows cadets' attitudes to the games used during the pedagogical experiment and obtained the most positive feedback.

Organization of Leisure Time in a Pandemic Period. Leisure time at the higher military educational establishment is organized in accordance with the following characteristics: cadets initiate leisure activities; leisure activity has a definite purpose; cadets may face difficulties while learning new movements; leisure time involve creativity; players should support of each other; expected satisfaction and enjoyment from leisure activities; all exercises are aimed at self-improvement within professional sphere $(27,28)$.

Taking these characteristics into consideration we planned two programs. The cadets of EG were trained in accordance with the program 1 that included: 2 hours of planned leisure time under supervision of faculty members or peers. The typical leisure schedule looked like the following: 30 min - icebreaking exercise; 60-80 min exercises to develop physical strength; 20-30 min - exercises with little physical activity. The cadets of CG were trained in accordance with the program 2 and during 2 hours they did regular free time activities. There was no typical leisure schedule for CG.

At the end of working day, the cadets filled in the forms to assess their mood, readiness to perform professional activities, physical shape, and existence of negative psychological states. Besides, we monitored the cadets' educational outcomes at the end of each week.

Research Instruments. We designed two types of the questionnaire forms to assess the quantitative and descriptive indicators of games effectiveness. The form to assess descriptive indicators included 12 questions about cadets' feelings, behavior, likes or dislikes, changes in daily routine. The research group analyzed the answers and divided them into two categories: having positive and negative impacts. Afterwards, the researchers provided the weekly reports to describe the advantages and disadvantages of games. The activities the cadets found very interesting and advantageous were used repeatedly. The form to assess quantitative indicators helped to obtain precise figures necessary for the experiment. The cadets participating in the survey rated the games from 0 to 5 on the basis of 21 positive characteristics given to the exercises.

Using the study records we calculated the cadets' weekly average marks to show the changes of educational outcomes. According to the research hypothesis the cadets' educational outcomes were expected to increase. We supposed that cognitive abilities would improve due to stress reduction and diminishing the pandemic fear.

In accordance, the research group calculated the cumulative indicator of effectiveness of sport and traditional games. This indicator scored the 
effectiveness as follows: insufficient, low, moderate, high, and very high. The availability of degree of effectiveness was represented in absolute numbers and in percentage.

Table 1. Description of Games by Cadets

\begin{tabular}{|c|c|}
\hline Game & Cadets' attitudes \\
\hline \multicolumn{2}{|l|}{ Classical sport team games } \\
\hline Volleyball & Interesting, competitive, team-building, energetic, cheerful \\
\hline Football & Energetic, motivating, well-known, favorite, team-building, most watched. \\
\hline Basketball & Difficult for short cadets, interesting, active, raising self-esteem, encouraging. \\
\hline \multicolumn{2}{|l|}{ Individual sports } \\
\hline Cycling & Helps to concentrate, easy, known from childhood, environment friendly. \\
\hline Kitesurfing & $\begin{array}{c}\text { Very interesting, encouraging, increasing courage and self-esteem, cheerful, increasing } \\
\text { mental capacity }\end{array}$ \\
\hline Badminton & Useful, develops concentration and accuracy, good for arms, active, energetic. \\
\hline Chess & $\begin{array}{l}\text { First military game, was invented in India, useful for future officers, develops tactics and } \\
\text { strategic thinking, increases concentration, needs patience. }\end{array}$ \\
\hline Draughts & Needs concentration, calm, relaxing. \\
\hline Table tennis & Easy, needs attention, energetic, develops leadership skills. \\
\hline \multicolumn{2}{|l|}{ Ukrainian traditional games } \\
\hline Hylka & Interesting, active, similar to cricket. \\
\hline Kovinky & Energetic, funny, interesting, motivating, team-building. \\
\hline Shvaika & Easy, does not require special equipment, was very popular in the past. \\
\hline Long rod & Funny, interesting, energetic, teaches how to help each other in a team. \\
\hline Tight bench & Funny, interesting, a nice demonstration of folk traditions. \\
\hline Cat and mouse & Relaxing, well known from childhood. \\
\hline Who is whispering? & $\begin{array}{c}\text { Easy, calm, relaxing, helps to concentrate, strengthens attention and patience, improves } \\
\text { memory, icebreaking exercise. }\end{array}$ \\
\hline Twig & Creative, fast, cheerful, develops attention and quick reaction. \\
\hline \multicolumn{2}{|l|}{ Foreign traditional games } \\
\hline Tag & Very active and energetic, does not require special equipment or much time. \\
\hline Kick-to-kick & Interesting, competitive, improves physical shape, energetic. \\
\hline Musical chairs & $\begin{array}{c}\text { Funny, interesting, improves quick reaction, good icebreaking game, can be played inside } \\
\text { and outside. }\end{array}$ \\
\hline Paper football & $\begin{array}{c}\text { Simple version of football, very easy, sometimes can be a bit boring and childish, can be } \\
\text { played not very often. }\end{array}$ \\
\hline Tug of war & Well known, very competitive, interesting, active, energetic. \\
\hline Jumping Jack & $\begin{array}{l}\text { Used as a physical jumping exercise in the US military, very useful, simple, very effective } \\
\text { for quick workout, can be played while watching TV or listening to radio. }\end{array}$ \\
\hline Truth or dare? & Interesting, can be played in English, improves memory and creativity. \\
\hline I spy & Funny, improves creativity, icebreaking exercise, can be played in English. \\
\hline $\begin{array}{l}\text { Here comes an old } \\
\text { soldier }\end{array}$ & $\begin{array}{c}\text { Interesting, useful to make friends, improves memory and creativity, increases vocabulary, } \\
\text { good icebreaking game. }\end{array}$ \\
\hline Skipping rope & $\begin{array}{l}\text { Interesting, known from childhood, improves physical shape, energetic, active, good } \\
\text { warming-up exercise, very popular among female cadets. }\end{array}$ \\
\hline Hopscotch & Active, energetic, suitable for female cadets. \\
\hline Gulli-Danda & $\begin{array}{l}\text { Interesting, active, requires quick reaction, improves physical shape, good to keep fit, very } \\
\text { funny and loud. }\end{array}$ \\
\hline Gulel & Active, energetic, improves accuracy and reaction. \\
\hline Sampholia & Energetic, active, interesting, competitive, suitable for big teams, improves team-building. \\
\hline \multicolumn{2}{|l|}{ Martial arts } \\
\hline Boxing & Well known, most watched, useful, improves physical shape, popular among male cadets. \\
\hline Taekwondo & Interesting, useful, improves mental health and physical shape. \\
\hline Judo & Active, energetic, competitive, interesting, helps to demonstrate endurance. \\
\hline Fencing & Interesting, requires attention and patience, useful, improves reaction. \\
\hline Gatka & Not usual, interesting, improves physical shape and readiness to self-defense. \\
\hline Horting & Interesting, active, requires quick reaction. \\
\hline Combat Hopak & Interesting, active, good exercises, requires strength and endurance, unique. \\
\hline Silambam & Interesting, active, useful, good for physical shape, improves quick reaction. \\
\hline
\end{tabular}

\section{RESULTS}

The descriptive analysis showed that sport and traditional games are interesting and motivating; the cadets do not need much time to learn the rules. The young people felt interested, active, enthusiastic, and encouraged. They liked the presence of a 
facilitator when they played for the first time, but when they were involved repeatedly the cadets prefer to play independently. The most importantly, sport and traditional games received generally positive evaluations from female cadets who are more inclined to passive recreation. And the cadets who are originated from rural territories and got used to play different outdoor games from their childhood admitted significant role of sport and traditional games. Therefore, we distinguished 25 descriptive indicators. They include: time necessary for home assignment; time management; additional project participation; creativity; foreign language acquisition; physical shape; motivation to professional activities; motivation to learning activities; mood; fear of pandemic; adaptability to extreme conditions; leadership skills; discipline; team-building; cognitive abilities; socialization; communication skills; stress management; aggression management; independence in decision making; independence to carry out tasks; ability to concentrate; memory improvement; pedagogical competence; respect to traditions.

Figure 1 shows the comparative results for the analysis of descriptive indicators for EG and CG. It represents the number of positive answers (in percentage) for questions used in the type one form during 20 weeks. The results show that the cadets of EG had positive dynamics in all indicators.

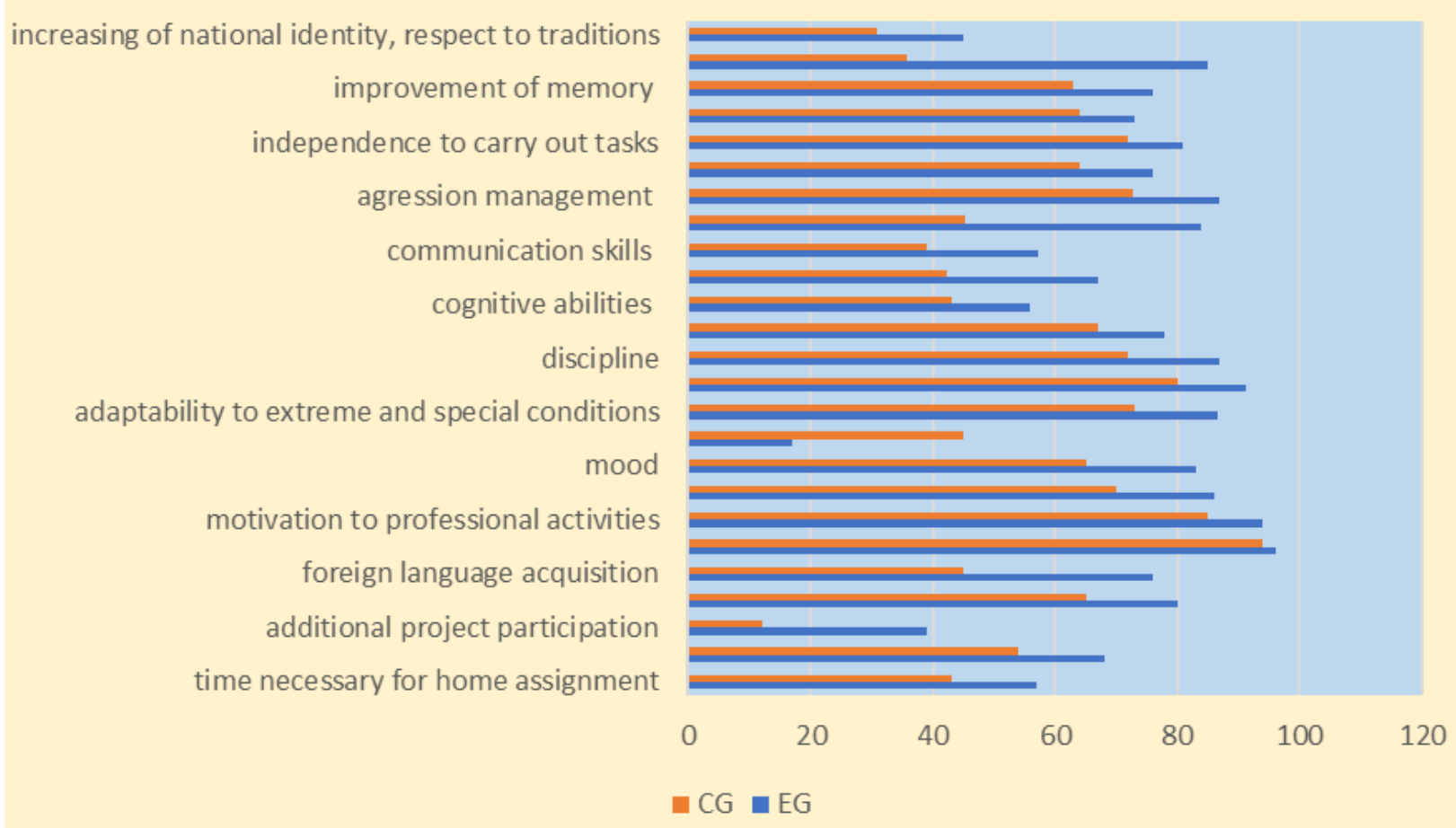

Figure 1. Comparative Analysis of Descriptive Indicators for EG and CG, (\%)

Figure 2 shows the results of comparative analysis of quantitative indicators for $\mathrm{EG}$ and $\mathrm{CG}$. The lines represent the cadets' evaluation of characteristics of sport and traditional games in marks from 0 to 5 , where 0 means absence of effect, 1 means very low effect, 2 means very bad effect with unsystematic or rare positive manifestations that do not lead to improvement of personality condition, 3 - sufficient effect, 4 good effect, 5 - frequent or permanent positive effect that leads to significant improvement of personality condition. The results show that the cadets from EG evaluated sport and traditional games with positive marks. This indicates that the choice of activities was correct and facilitators managed to organize the group to obtain positive effect leading to improvement of future military officer's personality despite of a pandemic period at the higher military educational establishment. The cadets of CG were involved in self-organized leisure activities and the results show that they spend time relaxing with rare positive effect for learning activities or future professional job. The cadets of CG demonstrated lower ability to manage stress caused with COVID-19 and faced more frequent issues like mood swings, 
communication problem, inability to manage time, unwillingness to compromise or participate in different activities.

The analysis of the study records books showed that the cadets of EG demonstrated better educational outcomes and were more often ready with their home assignments. The cadets of $\mathrm{CG}$ paid less attention to their tasks and they were inactive in the classroom. In average the cadets of CG needed 25 minutes more to do their home assignments. The regular randomized survey among instructors of the Academy showed that they were satisfied with progress in EG as they usually assessed the cadets' achievements with positive marks. But the cadets of CG more often got negative marks for completion of classroom tasks and home assignment. Also, the cadets of EG were more interested in participating in additional extra-curriculum projects. This indicates that even two-hour daily well-organized leisure activities improve personality condition and reducing stress or fear.

The effectiveness of sport and traditional games was calculated using descriptive and quantitative indicators and progress of cadets' educational outcomes. The weekly indicator of effectiveness was measured in accordance with the following equation:

$\mathrm{WE}_{\mathrm{i}}=\mathrm{D}_{\mathrm{i}}+\mathrm{Q}_{\mathrm{i}}+\mathrm{P}_{\mathrm{e}}$,

where $\mathrm{WE}_{\mathrm{i}}$ - indicator of weekly effectiveness; $D_{i}-$ descriptive indicator; $Q_{i}-$ quantitative indicator; $\mathrm{P}_{\text {eo }}$ - cadets' progress of educational outcomes.

$\mathrm{WE}_{\mathrm{i}}$ is evaluated in five degrees - very high, high, moderate, low, and insufficient. For each degree the certain number of points was established, as follows: very high degree $=100$ 90 points; high degree $=89-75$; moderate degree $=74-55$; low degree $=54-31$; insufficient degree $=30-0$.

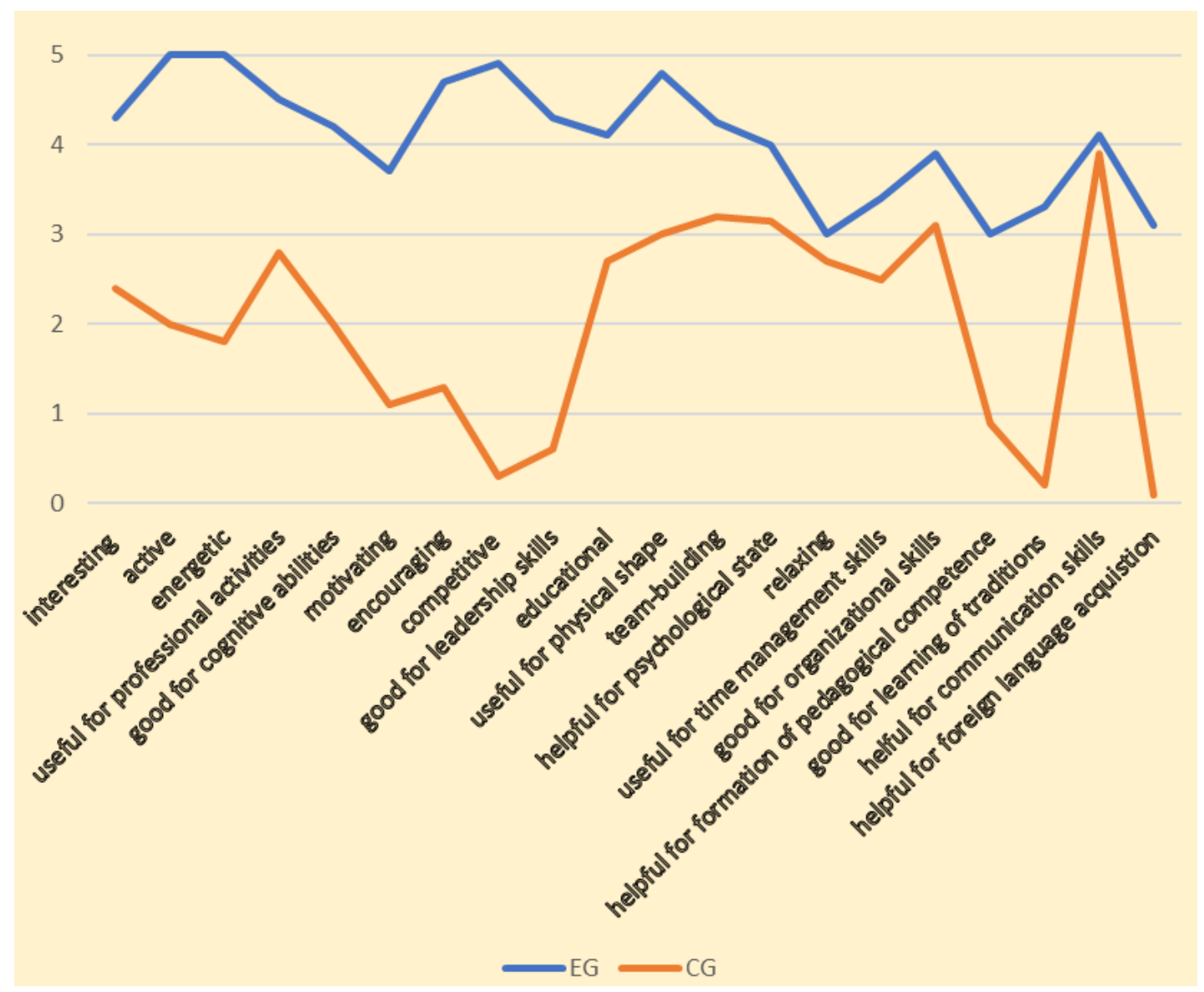

Figure 2. Comparative Analysis of Quantitative Indicators for EG and CG

Afterwards, the percentage for each degree was calculated on the basis of received cumulative indicator. Table 2 shows weekly reports on evaluation on effectiveness of games used for EG. Table 3 shows the evaluation of selforganized leisure time for $\mathrm{CG}$ at the higher 
military educational establishment in a pandemic time.

Then the difference in degrees between the input and outcome numbers in EG and CG was measured:

$\mathrm{DIF}_{\mathrm{EG}}=\mathrm{ON}_{\mathrm{DE}}-\mathrm{IN}_{\mathrm{DE}} ; \mathrm{DIF}_{\mathrm{CG}}=\mathrm{ON}_{\mathrm{DE}}-\mathrm{IN}_{\mathrm{DE}}$,

where DIF means the difference between numbers; DE - degree of effectiveness; ON outcome number; IN - input number.

EG shows that the usage of sport and traditional games was effective psychological and pedagogical technology at the higher military educational establishment. To be more specific, the largest increases were registered for high and moderate degrees of effectiveness.
By contrast, the differences between input and outcome data in the CG were not sufficient. The self-organized or poor-organized leisure activities caused minor improvements in psychological condition or slight increase in cognitive abilities after ten weeks the experiment was started. The differences between input and outcome numbers in EG and $\mathrm{CG}$ are the following: very high degree of effectiveness is 3,6 for the EG and 0,6 for the CG; high degree $-7,8$ and 1,4 respectively; moderate degree - 5,6 (EG) and 2,8 (CG); low degree is $-3,3(\mathrm{EG})$ and $-2,5(\mathrm{CG})$; insufficient degree is $-13,7$ (EG) and $-2,3$ (CG).

Table 2. Evaluation on Effectiveness of Sport and Traditional Games used for EG, (\%)

\begin{tabular}{lccccc}
\hline & Very high & High & Moderate & Low & Insufficient \\
\hline W1 & 9 & 23 & 30 & 14 & 24 \\
W2 & 8 & 27 & 31 & 13 & 14 \\
W3 & 9.5 & 26.8 & 32 & 15 & 17.7 \\
W4 & 9 & 27.3 & 32.1 & 14.8 & 16.6 \\
W5 & 9.1 & 27.6 & 32 & 14.5 & 16.5 \\
W6 & 9.2 & 27.9 & 33 & 15 & 15.4 \\
W7 & 9.1 & 27.5 & 33.5 & 16.1 & 14.4 \\
W8 & 9.3 & 27 & 33 & 16.4 & 13.8 \\
W9 & 9.5 & 27.1 & 33.2 & 16.1 & 14.1 \\
W10 & 9.6 & 27.2 & 33.4 & 16 & 14 \\
W11 & 9.8 & 27.3 & 33.3 & 16.2 & 13.6 \\
W12 & 10 & 27.5 & 33.9 & 13.4 \\
W13 & 10 & 27.8 & 34 & 14.2 & 13.5 \\
W14 & 9.9 & 28.1 & 34.3 & 14 & 13.5 \\
W15 & 10.2 & 35.1 & 13.7 & 13.1 \\
W16 & 10.5 & 29.6 & 35.9 & 13 & 13.1 \\
W17 & 10.8 & 30.3 & 35.5 & 12.5 & 11.4 \\
W18 & 11.1 & 30.8 & 10.7 & 10.4 \\
W19 & 12.4 & & 35.6 & 10.3 \\
\hline
\end{tabular}

Table 3. Weekly Reports on Evaluation of Leisure Time for CG, (\%)

\begin{tabular}{lccccc}
\hline & Very high & High & Moderate & Low & Insufficient \\
\hline W1 & 2 & 11 & 23 & 38 & 26 \\
W2 & 2.1 & 10.8 & & 37.9 & 25.2 \\
W3 & 1.8 & 11.2 & 23.6 & 38.5 & 24.9 \\
W4 & 1.9 & 11.1 & 23.7 & 38.6 & 24.7 \\
W5 & 2.2 & 10.9 & 24.1 & 38.3 & 24.5 \\
W6 & 1.7 & 10.8 & 23.9 & 38.2 & 25.4 \\
W7 & 1.8 & 11.1 & 24 & 25.3 \\
W8 & 1.9 & 11.2 & 24.2 & 39 & 23.8 \\
W9 & 2 & 11.3 & 24.3 & 38 & 24.5 \\
W10 & 2.1 & 11.4 & 24.2 & 37.8 & 24.6 \\
W11 & 2.2 & 11.3 & 24.3 & 37.7 & 24.4 \\
W12 & 2.1 & 11.5 & 24.4 & 37.6 & 24.8 \\
W13 & 2.2 & 11.4 & 24.7 & 36.8 & 24.9 \\
W14 & 2.2 & 24.8 & 36.2 & 25.5 \\
W15 & 2.3 & 11.6 & 24.7 & 25.1 \\
W16 & 2.3 & 25 & 36.5 & 24.7 \\
W17 & 2.4 & 11.8 & 25.1 & 36 & 24.5 \\
W18 & 2.5 & 12.2 & 35.9 & 24.3 \\
W19 & 2.5 & 12.3 & 25.2 & 36.1 & 23.9 \\
W20 & 2.6 & 12.4 & 35.5 & 23.7 \\
\hline
\end{tabular}


The effectiveness of sport and traditional games raised the question how to use this technology in a post-pandemic period. The results of the experiment confirm that the games help the cadets improve social interaction; increase emotional stability; raise physical endurance; change the attitudes towards themselves and build up optimistic outlook; improve adaptability to existing situation, extreme or special conditions in particular; form social support and openness. These changes, in the long run, will lead to the increase in professional effectiveness, enhance educational outcomes, improve stress and aggression management skills, increase leadership skills and creativity. Besides, it was observed that traditional games enhances morality and increase the respect to other people's traditions. Mutual physical activities can be positive for creation of favourable psychological atmosphere in the team. As a result, the model of using sport and traditional games in a post-pandemic period was developed (Figure 3).
To implement this model effectively we formulated the following recommendations:

1) The game can be facilitated by a faculty member or a peer.

2) All players should concentrate on the game and check the time.

3) The activities should vary.

4) It is required to diminish the supervision and allow the cadets to organize their activities as they wish to avoid exhaustion and overloading.

5) It is not recommended to play sport or traditional games in big groups.

6) Some games can be used during physical training lessons. Later some sport and traditional games can be used sporadically as an element of fun and relaxation.

7) Games can be used during peer-to-peer learning or independent learning.

8) Sport and traditional games are the most effective during first year or basic training.

9) The facilitator controls the discipline. If the rules are violated, it is recommended to stop the game.

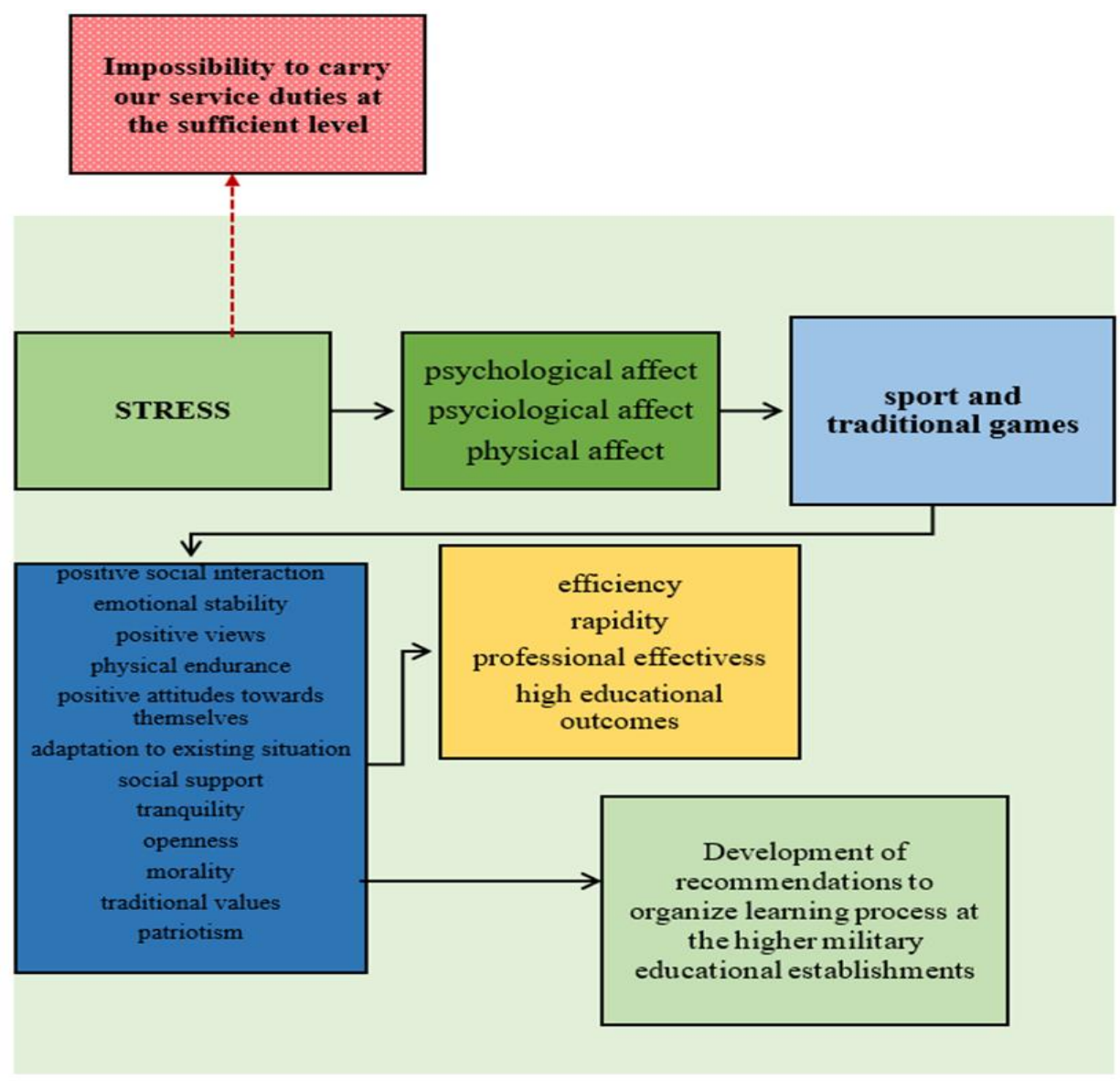

Figure 3. The Model of Usage of Sport and Traditional Games in a Post-Pandemic Period 
10) The game rules should be simple.

11) Sport and traditional games should involve physical movements.

12) Sport and traditional games can be used in mixed study groups where the players are of different age and have different professional experience.

13) It is recommended to prefer outdoor games to indoor ones.

14) It is required to pay more attention towards the female cadets' participation as they prefer intellectual activities like reading, doing crossword puzzles, etc.

15) Foreign traditional games can be played using foreign language to improve sociolinguistic competence and increase foreign language communicative competence.

16) Sport and traditional games do not require special equipment and preliminary training.

17) Sport and traditional games can be used during breaks between lessons.

18) The cadets should be explained that the most of their activities within the higher military educational establishment should be used for the benefit of their future profession.

This study had some limitations. First, the research involved only the cadets studying at the higher military educational establishments where the organization of educational process is different from other institutions. Second, the choice of sport and traditional games applied during the experiment does not oblige the scientific staff and faculty members to use those kinds of activities in order to improve psychological condition and learning outcomes of the learners. We insist on free choice of games to design the special program of implementation of psychological and pedagogical technology but, at the same time, we require to combine different activities like icebreakers, exercises to develop physical strength and exercises with little physical activity.

\section{CONCLUSION}

The study showed that the usage of sport and traditional games was effective at the higher military educational establishment in a pandemic period. We registered the largest increases for high and moderate degrees of effectiveness. The pedagogical experiment proved that sport and traditional games contribute to the improvement of the cadets' social interaction within the study group, increase their emotional stability, positive views, and physical endurance. Also, such exercises build up an optimistic outlook and make cadets more adaptive to special or extreme conditions. The future military officers involved in well-organized leisure activities on a regular basis demonstrated better psychological condition and cognitive abilities. Moreover, the cadets from EG showed higher learning outcomes, they were more active in the classroom and they were eager to be involved in scientific projects and extra-curriculum activities. In the long run, this will lead to an increase in professional effectiveness, operational efficiency and rapidity, higher educational outcomes, formation of stress management abilities, leadership skills and creativity, increasing the respect to other people's traditions. Such positive effects of sport and traditional games create favorable conditions to implement this psychological and pedagogical technology in a post-pandemic period. The conclusion from the experiment was to design the model of usage of sport and traditional games at the higher military educational establishment and the formulation of the recommendations for its implementation.

Stress management topic is a very important aspect of the professional competence of future military specialists both theoretically and practically.

\section{APPLICABLE REMARKS}

- Sport and traditional games are recommended to be introduced within the educational process at the higher military educational establishments.

- In the field of professional military training, it is suggested that sport and traditional games should increase the emotional stability, positive views, and physical endurance of cadets.

- It is recommended for military pedagogues and faculty members to implement the model of usage of sport and traditional games at the higher military educational establishment.

\section{ACKNOWLEDGMENTS}

The study was supported by the Military Academy (Odesa, Ukraine). All the participants of the research (156 first-year cadets) were informed about the pedagogical experiment and took part voluntarily in accordance with the ethical requirements of such types of research. We thank them for their active participation and incredible help.

\section{DECLARATION OF INTEREST}

The authors declare that there are no conflicts of interest. 


\section{REFRENCES}

1. Dergaa I. COVID-19 Vaccination, Herd Immunity and The Transition Toward Normalcy: Challenges with The Upcoming Sports Event. Annal Appl Sport Sci. 2021;9(3).

2. Pao-Lung C, Yi-Ming Y. Resilience and Covid-19: action plans and strategies in a military community. Asia Pacific J Soc Work Develop. 2021;31(1-2):115-122. doi: 10.1080/02185385.2020.1828156

3. Trabelsi K, Ammar A, Masmoudi L, Boukhris O, Chtourou H, Bouaziz B, et al. Sleep Quality and Physical Activity as Predictors of Mental Wellbeing Variance in Older Adults during COVID-19 Lockdown: ECLB COVID-19 International Online Survey. Int J Environ Res Public Health. 2021;18(8). doi: 10.3390/ijerph18084329 pmid: 33921852

4. Sharma S. Occupational stress in the armed forces: An Indian army perspective. IIMB Manage Rev. 2015;27(3):185-195. doi: 10.1016/j.iimb.2015.06.002

5. Trudeau F, Shephard RJ. Physical education, school physical activity, school sports and academic performance. Int J Behav Nutr Phys Act. 2008;5:10. doi: 10.1186/1479-5868-5-10 pmid: 18298849

6. Hwang TJ, Rabheru K, Peisah C, Reichman W, Ikeda M. Loneliness and social isolation during the COVID-19 pandemic. Int Psychogeriatr. 2020;32(10):1217-1220. doi: 10.1017/S1041610220000988 pmid: 32450943

7. Gallagher MW, Zvolensky MJ, Long LJ, Rogers AH, Garey L. The Impact of Covid-19 Experiences and Associated Stress on Anxiety, Depression, and Functional Impairment in American Adults. Cognit Ther Res. 2020:1-9. doi: 10.1007/s10608-020-10143-y pmid: 32904454

8. Bray RM, Camlin CS, Fairbank JA, Dunteman GH, Wheeless SC. The Effects of Stress on Job Functioning of Military Men and Women. Armed Forces Soc. 2001;27(3):397-417. doi: 10.1177/0095327X0102700304 pmid: 20543977

9. Cheema SS, Grewal DS. Meditation for stress reduction in Indian Army- An Experimental Study. $J$ Business Manage. 2013;10(2):27-37. doi: 10.9790\%2F487x-1022737

10.Hagger MS, Keech JJ, Hamilton K. Managing stress during the coronavirus disease 2019 pandemic and beyond: Reappraisal and mindset approaches. Stress Health. 2020;36(3):396-401. doi: 10.1002/smi.2969 pmid: 32588961

11.Patterson GT. Predicting the effects of military service experience on stressful occupational events in police officers. Polic Int J. 2002;25(3):602-618. doi: 10.1108/13639510210437050

12. Singh VK, Adhikary R. Impact of Yoga Practices on Occupational Stress among Indian Army Personnel. Int J Yoga Allied Sci. 2016;5(2):108-112.

13. Mondal K, Majumdar D, Pramanik A, Chatterjee S, Darmora M, Majumdar D. Application of Yoga as an Effective Tool for Improving Postural Balance in Healthy Young Indian Adults. Int J Chinese Med. 2017;1(2):62-69. doi: 10.11648/j.ijcm.20170102.14

14. Ospina MB, Bond K, Karkhaneh M, Tjosvold L, Vandermeer B, Liang Y, et al. Meditation practices for health: state of the research. Evidence Report/Technol Assess. 2007;155:1-263.

15.Bu B, Haijun H, Yong L, Chaohui Z, Xiaoyuan Y, Singh MF. Effects of martial arts on health status: a systematic review. J Evid Based Med. 2010;3(4):205-219. doi: 10.1111/j.1756-5391.2010.01107.x pmid: 21349072

16. Griban GP, Yavorska TY, Tkachenko PP, Kuvaldina OV, Dikhtiarenko ZM, Yeromenko EA, et al. Motor activity as the basis of a healthy lifestyle of student youth. Wiad Lek. 2020;73(6):1199-1206. pmid: 32723953

17. Moore B, Dudley D, Woodcock S. The effect of martial arts training on mental health outcomes: A systematic review and meta-analysis. $J$ Bodyw Mov Ther. 2020;24(4):402-412. doi: 10.1016/j.jbmt.2020.06.017 pmid: 33218541

18. O'Hanlon R. Military Sports and the History of the Martial Body in India. J Economic Soc History Orient. 2007;50(4):490-523. doi: 10.1163/156852007783245133

19.Malm C, Jakobsson J, Isaksson A. Physical Activity and Sports-Real Health Benefits: A Review with Insight into the Public Health of Sweden. Sports (Basel). 2019;7(5). doi: 10.3390/sports7050127 pmid: 31126126

20.Tyler GJ. The "Goods of Sport" and Physical Education. J Physic Educat Recreat Dance. 2019;90(8):35. doi: 10.1080/07303084.2019.1649559 
21.Chen KWC, Chiu PK, Lin IA, Hsu KF, Hsu MC, Liang MTC. A Study of Basic Military Training on the Physical Fitness and Physical Self-Concept for Cadets. Asian J Physic Education Recreat. 2007;13(2):6-12. doi: 10.24112/ajper.131825

22. Ojanen T, Salonen A, Vasankari T, Kyröläinen H. Physical activity of soldiers during a military field exercise. J Sci Med Sport. 2017;20(2):113-114. doi: 10.1016/j.jsams.2017.09.419

23.Pomonaci M, Sabin I. Leisure sport activities and their importance in living a healthy and phycho-social life. Sci Bullet. 2018;1(45):36-42. doi: 10.2478/bsaft-2018-0005

24. Trainor S, Delfabbro P, Anderson S, Winefield A. Leisure activities and adolescent psychological wellbeing. J Adolesc. 2010;33(1):173-186. doi: 10.1016/j.adolescence.2009.03.013 pmid: 19406463

25.Stebbins RA. Obligation as an Aspect of Leisure Experience. J Leisure Res. 2000;32(1):152-155. doi: 10.1080/00222216.2000.11949906

26.Thompson MD, Meldrum K, Sellwood J. "...it is not just a game": Connecting with Culture through Traditional Indigenous Games. America J Educat Res. 2014;11(2):1015-1022. doi: 10.12691/education2-11-3

27.Herrador-Colmenero M, Fernández-Vicente G, Ruiz JR. Assessment of physical fitness in military and security forces: a systematic review. Europe J Human Move. 2014;32:3-28.

28. Özdemir AS. Serious Leisure Perspectives in Sports: Professional Athletes' Career Progress via Serious Leisure. Asian J Educat Train. 2020;6(2):186-195. doi: 10.20448/journal.522.2020.62.186.195 